\title{
A espacialidade do poder na Cidade Grega Antiga
}

\author{
Elaine Farias Veloso Hirata
}

Universidade de Sáo Paulo

O espaço comanda os corpos prescrevendo ou proscrevendo gestos, rotas e distâncias a serem cobertas... Monumentalidade... sempre incorpora e impóe uma mensagem claramente inteligível. Edificaçóes monumentais mascaram o desejo do poder e a arbitrariedade do poder sob signos e superfícies que clamam expressar desejo coletivo e o pensamento coletivo. ${ }^{1}$.

Nas ultimas décadas, os estudos sobre a antiga cidade grega - a polis revelam uma crescente aproximação entre arqueólogos e historiadores, tendo o estudo do espaço com um campo de investigação em comum² ${ }^{2}$ As análises das paisagens formadas pela culturalização do ambiente que resulta das interaçôes homem-ambiente, homem-homem e ambiente-ambiente, ampliaram a ótica dos arqueólogos, antes centrada no sítio, para unidades territoriais maiores e que revelam padróes, linhas de tendência, redes de significados. $\mathrm{O}$ arqueólogo e etnógrafo Hamish Forbes resume assim a mudança:

Analisando no tempo os padróes de surgimento e desaparecimento de sítios em uma região, e a variação dos níveis de artefatos entre sítios, os arqueólogos reconheceram que estavam estudando as histórias contínuas das paisagens regionais e não simplesmente conjuntos de sítios ${ }^{3}$.

\footnotetext{
${ }^{1}$ H. ,LEFEBVRE. The production of Space. Trans. D. Nicholson-Smith, Oxford: Blackwell, 1991,p.143; M.P., PEARSON; C., RICHARDS (Eds.). Architecture and Order. Approaches to Social Space. London: Routledge, 1994,p.03

${ }^{2}$ Mesmo o Copenhagen Polis Center $(C P C)$, centro de excelência no levantamento das fontes textuais sobre as pólis, que resultou no $[A n]$ Inventory of Archaic and Classical Poleis, obra fundamental para quem inicia uma pesquisa no tema,vem apresentando em suas publicaçóes um volume significativo de trabalhos voltados para a materialidade e a espacialidade da polis.

${ }^{3}$ H., FORBES. Meaning and Identity in a Greek Landscape An Archaeological Ethnography. Cambridge: Cambridge University Press, 2007, p.15.
} 
Sinteticamente poderíamos afirmar que hoje, arqueólogos e historiadores entendem a paisagem como a totalidade do mundo exterior que resulta da mediação realizada pela experiência humana subjetiva, ou, em outros termos, a terra se transformando em paisagem pela atividade e percepção humana ${ }^{4}$.

A arqueologia da paisagem, expressão guarda-chuva que, na teoria arqueológica contemporânea abriga tendências e abordagens por vezes conflitantes, é historicamente o resultado do interesse crescente de arqueólogos e historiadores pelo estudo do espaço em sua dimensão social ${ }^{5}$, enquanto a arena onde a prática política tem lugar concretamente. Ao se voltar para a vida política, a disciplina arqueológica confronta-se com as dificuldades na compreensão da autoridade, do poder, por meio dos lugares, dos vestígios dos ambientes construídos que expressam o processo contínuo de modelagem e remodelagem das paisagens, efetivado pelos homens.

Antes de prosseguir, no entanto, é importante pontuar e definir alguns conceitos básicos para o andamento da discussão, são eles: espaço,lugar e paisagem. Usados muitas vezes como sinônimos, na verdade comportam uma grande variedade de acepçôes relacionadas às correntes de pensamento ou às áreas de conhecimento de quem os utiliza.

No campo das humanidades, espaço é visto como um conceito muito abrangente, descrito pelo arqueólogo A. T. Smith como "uma rubrica filosófica sob a qual todos os problemas relacionados à extensão e aos parâmetros das relaçôes sincrônicas podem ser discutidos" ${ }^{6}$. O geógrafo Milton Santos o considera

uma instância da sociedade, ao mesmo tempo em que a instância econômica e a instância cultural-ideológica. Isso significa que, como instância ele contem e é contido pelas demais instâncias ,assim como cada uma delas o contem e é por ele contida” e conclui: “..a essência do espaço é social".

\footnotetext{
${ }^{4}$ A. T., SMITH. The Political Landscape - Constellations of Authority in Early Complexes Polities. Berkeley and Los Angeles: University of California Press, 2003, p.10.

${ }^{5}$ Como introdução ao tema, recomendamos a leitura do Handbook of Landascape Archaeology (Eds. B.David e J.Thomas) publicado em 2010, que fornece uma visão panorâmica , em tempos e espaços diferentes, das abordagens do espaço ...

${ }^{6}$ A. T. SMITH. The Political Landscape - Constellations of Authority in Early Complexes Polities. Berkeley and Los Angeles: University of California Press, 2003, p.32.

${ }^{7}$ Milton, SANTOS. Da Totalidade ao Lugar. São Paulo: EDUSP, 2008, p.12.
} 
Os dois autores tomam o conceito de espaço como uma categoria relacional, não uma categoria absoluta e autônoma ${ }^{8}$,que independe da interação com os objetos e sujeitos que a integram, como era a concepção de espaço newtoniana. Em nossa visão, há certamente uma relação entre espaço e prática social e, assim, a possibilidade de entender a prática por meio do estudo do espaço é o fio condutor de nossa investigação.

Os lugares emergem dentro de histórias especificas', para o geógrafo YiFu Tuan (1977) o conceito de lugar refere-se a como específicos locais incorporam-se em mundos maiores de açóes e de significados humanos. Estudando questóes de linguagem e de lugar entre os Apaches do Arizona, Basso define lugar como "onde a historia, tanto humana quanto outra qualquer, acontece e onde o conhecimento obtido pela história viva reside" ${ }^{10}$. O conceito de lugar, pois, permite a particularização do espaço ao relacionar a específicas localizaçóes, significados construídos diacronicamente pela agência de seus habitantes. Aqui fica clara a diferença fundamental entre lugar e sítio, um construto artificial, oriundo de uma abordagem não-êmica da instância espacial de uma sociedade.

O temo landscape - paisagem - deriva do holandês landschap e é incorporado ao inglês, no final do séc. XVI; landschap, por sua vez, deriva da matriz germânica landschaft e com ela compartilha o sentido de unidade de ocupação humana - uma jurisdição, na verdade-quanto qualquer coisa que pudesse ser o aprazivel objeto de uma pintura ${ }^{11}$. No século 20, o geógrafo norteamericano Carl Sauer estabeleceu o conceito de paisagem cultural ao relacionar homem e meio ambiente e destacar a ação antrópica na construção de paisagens. Hoje, após um longo percurso de debates, persistem ainda muita

\footnotetext{
${ }^{8}$ Uma discussão extremamente interessante sobre o desenvolvimento histórico das concepçôes de espaço absoluto e espaço relacional e sua aplicação em vários campos de conhecimento, é apresentada no texto Sublimated Spaces. A. T. SMITH. The Political Landscape. Constellations of Authority in Early Complex Polities.University of California Press, Berkeley e Los Angeles,2003, p.30-77.

${ }^{9}$ Ibidem, p.32

${ }^{10}$ B., BOWSER e M.N., ZEDEÑO (Eds. ) - The Archaeology of Meaningful Places.University of Utah Press,Salt Lake City, 2009, p.1.

${ }^{11}$ S. SCHAMMA. Paisagem e Memória.1a. ed. 1995.Trad. Bras. Companhia das Letras,São Paulo , 2009.
} 
diversidade e ambigüidade no uso do conceito. Em nossa perspectiva, paisagem é um conceito que amplia espacial e temporalmente a noção de lugar e tomamos como nossa a definiçáo de Smith, que afirma:

As paisagens surgem da produção historicamente realizada de laços que ligam espaços (como formas delimitando experiências físicas), lugares (como estéticas geográficas ou construídas que agregam significados aos lugares) e representaçóes (como cartografias imaginadas de mundos possíveis) ${ }^{12}$

Assim, hoje, as paisagens não podem mais ser vistas como cenários da ação humana e sim como uma dimensão crítica no estudo das práticas sociais e estas sim se constituem no foco primordial de nossa análise, na preocupação em entender como, no caso das pólis gregas ${ }^{13}$, as práticas políticas operavam por meio das paisagens. A relação entre espaço e prática reitera o princípio da produção social da paisagem, mas, ao mesmo tempo, questiona a possibilidade dessa criação ser compartilhada igualmente pelos membros de uma sociedade. Esta disparidade é evidente e sinaliza a existência de relações assimétricas de poder,daí resulta que "o que faz o poder construir paisagens socialmente significantes é que a paisagem reflexivamente coloca limites nas práticas" ${ }^{14}$. Nas cidades contemporâneas, assim como nas cidades antigas, a circulação diária dos indivíduos ocorre e ocorria em espaços modelados por uma parcela de seus habitantes, ou seja, os que detêm os meios de construir essa paisagem e que por conta disso concentram as habilidades para "influenciar, regular, delimitar $e$ controlar a vida cotidiana" ${ }^{15}$.

A paisagem, como produto social, encapsula espaço e tempo, é

\footnotetext{
${ }^{12}$ A. T., SMITH. The Political Landscape - Constellations of Authority in Early Complexes Polities. Berkeley and Los Angeles: University of California Press, 2003,p.11.

13 " $n a$ análise do mundo grego, o conceito de territorialidade é indissociável da noção de espaço definido politicamente, ou seja, de um espaço ligado ao homem e à sua identidade politica". F., VERONESE. Lo spazio e la dimenzione del sacro. Santuari Grecia e territorio nella Sicilia arcaica. Padova: Esedra Editrice, 2006, p.18.

${ }^{14}$ A, T. SMITH. The Political Landscape - Constellations of Authority in Early Complexes Polities. Berkeley and Los Angeles: University of California Press, 2003, p.70.

${ }^{15}$ Ibidem, p.70.
} 
modelada e, por sua vez modela os que vivem nela ${ }^{16}$ e é remodelada de forma contínua através dos tempos. A temporalidade é uma dimensão indissociável da espacialidade. $\mathrm{O}$ espaço, que se define pelas relaçóes que se estabelecem entre seres vivos e coisas materiais, deve ser visto como o produto de negociaçóes no âmbito de um processo competitivo que envolve sujeitos com capacidades diferenciadas de modificar essas relaçóes ${ }^{17}$.

Nesta perspectiva, impóe-se a percepção de que, ao lado da temporalidade, a espacialidade é um instrumento heurístico obrigatório para a análise das práticas sociais e, no bojo destas, das relaçôes de poder. Mas, em se tratando de sociedades desaparecidas, como poderá o arqueólogo identificar as relações de poder no registro arqueológico? O poder, em uma definição ligeira $^{18}$, significaria a capacidade de um indivíduo ou de um grupo de indivíduos de exercer controle sobre outros indivíduos ou sobre coisas, espaços, gerando uma relação assimétrica entre os atores envolvidos neste processo. A busca do arqueólogo pela identificação de relaçóes de poder no registro material objetiva, em primeira instância, a identificação do sistema de símbolos por meio do qual estas relaçóes são expressas, sempre levando em conta o dinamismo da realidade investigada. Na tentativa de reconstituição de uma paisagem antiga - onde tais símbolos podem ter sido impressos - na decifraçáo da imagética e do conjunto da cultura material o pesquisador tenta localizar a fisicalidade das representaçóes do poder $^{19}$.

\footnotetext{
${ }^{16}$ É de Winston Churchill a famosa frase "Nós modelamos nossos edifícios e depois eles nos modelam". Ibidem, p.72.

${ }^{17}$ Ibidem, passim.

${ }^{18}$ Uma discussão aprofundada sobre o conceito de poder,sua natureza e formas de exercício não teria sentido no escopo deste trabalho.Remetemos pois, o leitor, aos trabalhos de Smith e Veronese (2006) que estabelecem algumas premissas sobre o tratamento do tema em sociedades précapitalistas.

${ }^{19}$ A interpretação de A.T. Smith do regime e paisagem política urbana do sul da Mesopotâmia entre os períodos Ur III e Babilônico Antigo inicial (ca. 2119 - 1880 a.C) se constitui em um estudo de caso extremamente bem fundamentado teóricamente e com um conjunto amplo de fontes documentais que abrange da literatura (Epopéia de Gilgamesh) à imagética (relevos e estela figurados) e aos dados da paisagem com seus espaços construídos.(Smith,2003,especialmente Caps. 5 e 6,pp.184-270)
} 
Com estes objetivos em perspectiva, a abordagem tradicional que via na arquitetura do mundo antigo, principalmente a originalidade e beleza da manifestação artística cede lugar a análises do componente simbólico presente na monumentalidade de uma edificação em relação às demais ${ }^{20}$, na sua localização em local privilegiado quanto à sua visibilidade pelo número maior de indivíduos, nos tipos de objetos presentes em seu interior, na existência de dispositivos materiais de controle de acesso a determinadas áreas, por exemplo. Pelo registro arqueológico pode-se aferir um dispêndio excepcional de recursos e de energia - o consumo conspícuo - na construçáo, por exemplo, de muralhas cuja dimensão ultrapassa a necessidade defensiva para se tornar a manifestação concreta e duradoura do poder de um governante e de sua cidade. A energia transformada em trabalho por grandes contingentes de escravos, bem como a mobilização de artesãos altamente especializados implicam uma forma de controle dessas atividades por um poder centralizador forte. É, portanto, necessário analisar as relaçóes entre projetos construtivos, formas de poder e ideologia para que a explanação arqueológica tenha maior profundidade na análise das formaçóes políticas do mundo antigo ${ }^{21}$. Cito, a este respeito, as palavras da arqueóloga italiana Francesca Veronese, estudiosa das formas de expressão material do poder na Sicília antiga:

Estruturas monumentais tais como templos ou palácios, mas também sepulturas, estátuas, relevos ou pinturas são classes de evidências extremamente significativas em relação à expressão e à comunicação de ideologias por meio de sistemas simbólicos,visto que,em geral a serie de temáticas que simboliza relaçôes não igualitárias - isto é, de poder- é bastante limitada;de toda forma é a tal tipo de iconografia que se recorre,na falta de outros indícios, para reconstruir a configuração do poder político ${ }^{22}$.

\footnotetext{
${ }^{20}$ E. F. HIRATA. Monumentalidade e representaçóes do poder em uma polis colonial. In: M.B.B., Florenzano; E.F., HIRATA (Orgs.) Estudos sobre a Cidade Antiga. São Paulo: EDUSP, 2009, passim. ${ }^{21}$ Pearson e Richards (1994) observam na forma e disposição das estruturas arquitetônicas na paisagem a manifestação visual da ideologia que dá suporte a relaçóes sociais assimétricas, típicas de sociedades rigidamente hierarquizadas. Para esses autores, portanto, a relação entre ocupação do espaço e expressáo de poder é uma via de acesso privilegiada para o estudo da estruturaçáo social e política de uma sociedade.

${ }^{22}$ F. VERONESE. Lo spazio e la dimenzione del sacro. Santuari Grecia e territorio nella Sicilia arcaica.
} 
$\mathrm{O}$ arqueólogo Bruce Trigger ${ }^{23}$ ao estudar as relaçôes entre o poder e o espaço construído, defende o princípio de que, nas edificaçôes monumentais, ou seja, naquelas que excedem tanto em escala quanto em qualidade de construção as suas necessidades funcionais evidencia-se o chamado consumo conspícuo, uma prática que integra as estratégias de afirmação do poder em sociedades estratificadas. Para o autor, inspirado na teoria arqueológica de viés processualista, o controle de energia nas sociedades humanas, se constitui "[n]a mais fundamental e universalmente reconhecida medida de controle de poder", e daí decorreria que "o mais básico meio pelo qual o poder pode ser simbolicamente reforçado é através do consumo conspicuo de energia". ${ }^{24} \mathrm{Na}$ perspectiva de Trigger, a arquitetura monumental por tratar-se de recurso material de alta visibilidade e durabilidade a comunicar esse consumo extraordinário, ao ser associada a um governante ou a uma camada hegemônica impunha uma mensagem claramente inteligível pelo conjunto da sociedade: sinalizaria materialmente para a eternidade e imutabilidade de uma ordem social; por outro lado, poderiam mascarar o arbítrio com que o poder está sendo exercido clamando por representar a vontade e pensamento coletivos. Ao contrário, quando a relação entre uma edificação e o poder passa a ser percebida como a materialização da tirania, a destruição deste bem pode ser o símbolo da contestação do poder visto como ilegítimo. Nesta linha de interpretação, Smith afirma que "[...] a contestação da autoridade política - ... - se assenta em uma visão cartográfica, em uma compreensão espacializada dos locais de importância singular para a sua reprodução e transformação" e cita Georges Bataille, para quem a destruição da Bastilha em 1789 pode ser entendida como uma expressão da "animosidade do povo contra os monumentos que são os seus verdadeiros governantes" 25 .

Padova: Esedra Editrice, 2006, p.50.

${ }^{23}$ B. TRIGGER. "Monumental architecture: a thermodynamic explanation of symbolic behaviour" In: World Archaeology 22, 1990.

24 Para Trigger, o consumo conspicuo amplia uma perspectiva materialista do comportamento humano ao incorporar "vários aspectos significantes dos componentes ideacionais deste comportamento que aparecem no registro arqueológico". Ibidem, pp. 128, 132.

${ }^{25}$ A. T. SMITH. The Political Landscape - Constellations of Authority in Early Complexes Polities. Berkeley and Los Angeles: University of California Press, 2003, p.06. 
A situação que se constata nas apoikias gregas na Sicília reforça esta tese: os tiranos que se multiplicaram na região durante toda a história destas cidades instituíram a monumentalidade nas edificaçóes como uma forma própria de instituição de um marco simbólico de seu poder na paisagem ${ }^{26}$. Na verdade, a relação entre a tirania e a atividade construtiva monumental aparece já consolidada no pensamento político de Aristóteles (Política,V,1313b) e, além da Sicília, também a Jônia registra, precocemente, a atividade construtiva monumental como característica da atuação de tiranos como Polícrates, que dotou Samos de fontes suntuosas e obras hidráulicas grandiosas ${ }^{27}$. Estes exemplos reafirmam a tendência das sociedades estratificadas, onde a assimetria caracteriza o jogo pelo poder, projetarem na paisagem marcos arquitetônicos que sinalizam a sua forma de organização política.

Na Itália o estudo das Paesaggi di potere teve grande impulso graças ao arqueólogo A. De Guio que constituiu, na Universidade de Pádua, um centro de pesquisas que vem desenvolvendo modelos teóricos e testando-os em casos específicos como o fez Francesca Veronese (2006) em seu estudo sobre a Sicília antiga.

Em síntese, a arqueologia espacial italiana ao trabalhar no sentido de evidenciar, no território, a iconografia do poder, está, em ultima instância, atuando no campo da ideologia, definida assim por Veronese "não tanto... a superestrutura construida a posteriori para justificar uma ordem sócio-politica préconstituida, mas mais como uma forma de "auto-representação" do poder com conseqüências diretas na organizaçâo espacial’28.

\footnotetext{
${ }^{26}$ E. F., HIRATA. Monumentalidade e representaçóes do poder em uma polis colonial. In: M.B.B., Florenzano; E. F., HIRATA (Orgs.) Estudos sobre a Cidade Antiga. São Paulo: EDUSP, 2009.

${ }^{27}$ M. TORELLI, M. “Architettura greca di Sicilia:il ruolo dell'idelologia”. In: P., MINÁ. (org.). Urbanistica e Architettura nella Sicilia Greca. Palermo: Regione Siciliana, Assessorato dei Beni Culturali, Ambientali e della Pubblica Istruzione, 2005, p.08.

${ }^{28}$ F., VERONESE. Lo spazio e la dimenzione del sacro. Santuari Grecia e territorio nella Sicilia arcaica. Padova: Esedra Editrice, 2006, p. 51.
} 


\section{Um estudo de caso}

a distinção convencional entre religião e política obscurece a similaridade básica entre religiáo e política: ambas são formas de sistematicamente construir poder ${ }^{29}$

Ao publicar em 2006, "Lo spazio e la dimenzione del sacro. Santuari greci e território nella Sicilia arcaica" F. Veronese se propôs a analisar a relação entre a posse de terra, a constituiçáo de uma paisagem sagrada e a consolidaçáo do poder político na área cultural constituída pelas apoikias estabelecidas pelos gregos balcânicos na Sicilia, a partir do século VIII a.C.

A autora experimenta modelos teóricos fundamentados na arqueologia espacial ${ }^{30}$ na análise de um expressivo conjunto de dados empíricos obtidos pelo exame circunstanciado de 138 locais de culto documentados pelas escavaçóes arqueológicas realizadas em sítios ocupados por gregos e sítios em que o contato com as populaçóes locais é materialmente evidenciado. Nos sítios de Himera, Zancle, Naxos, Leontino, Catânia, Mégara Hibléia, Siracusa, Gela, Agrigento e Selinonte foram elencados, descritos e interpretados os locais de culto urbanos, suburbanos e extraurbanos ${ }^{31}$. Com vistas à constituição de um minucioso inventário dos dados empíricos relativos a cada local de culto, a autora estabeleceu 13 variáveis principais em torno das quais repertoriou as informaçóes:

1. Localização em relação à colônia: urbana, suburbana, extraurbana, extraurbana em centro indígena;

2. Contexto geomorfológico: em altitude, na planície, no cume, no sopé;

\footnotetext{
${ }^{29}$ S., PRICE. Ritual and Power The Roman Imperial Cult in Asia Minor. Cambridge: Cambridge University Press, 1984, p.247.

${ }^{30} \mathrm{~F}$. Veronese utiliza, de forma crítica,modelos de indagação territorial como E. S. $M$ (Early State Module) encampado por Renfrew nos anos 1980, os polígonos de Thyssen dos anos 1990, o modelo concêntrico centro-periferia de Taylour também dos anos 80 e o modelo X-TENT dos anos 1970, proposto por Renfrew para chegar aos "mapas de aéreas de influência". A autora analisa seus dados também com o suporte do GIS. O uso de fotomosaicos Landsat permite uma visão tridimensional das paisagens,indicando relevo,rios e demais elementos constituintes do meio ambiente. F., VERONESE. Lo spazio e la dimenzione del sacro. Santuari Grecia e territorio nella Sicilia arcaica. Padova: Esedra Editrice, 2006, pp. 79, 622-629.

${ }^{31}$ Sobre os critérios adotados para a definição destas categorias. Ibidem, pp.83-84.
} 
3. Contexto sociomorfológico na acrópole, na encosta da acrópole;

4. Posição topográfica em relaçâao a: muros, necrópoles, mar, rio, fonte, lago, pântano;

5. Características ambientais: presença de contrafortes rochosos, solo arenoso;

6. Articulação monumental: estrutura teatral anexa, templo pseudodíptero, períptero, hekatômpedo, conjunto de capelas, edifício sacro ou recinto, gruta, altar, deposito votivo externo, outras estruturas;

7. Orientação: este/oeste, norte/sul, nordeste-sudoeste, noroeste-sudeste, misto, não determinável;

8. Material votivo: em depósito, esporádico, deposiçóes particulares;

9. Atribuição do culto:segura, provável, não determinada, culto único, culto múltiplo;

10. Titularidade do culto: Deméter, Kore, Atena, Ártemis, Hera, Afrodite, Ninfas, Zeus, Apolo, Dioniso, Héracles, outro;

11. Freqüentação grega atestada do período: protoarcaico (VII-VII), arcaico (VI);

12. Abandonoldesaparecimento desde o periodo: arcaico (VI); clássico (V); helenístico (IV-III); outros;

13. Presença indígena: precedente, contemporânea.

A partir da constituição do banco de dados abrangendo os 138 locais de culto, os cruzamentos de dados foram realizados após distribuí-los em quatro macroáreas individualizadas de acordo com a matriz étnica dos fundadores das apoikias ${ }^{32}$ : 1. Macroárea eubóica (Himera, Zancle e Naxos, Catânia e Leontinos); 2.Macroárea megarense (Megara Hibléia e Selinonte); 3.Macroárea coríntia (Siracusa, Eloro, Acrae, Casmene e Camarina) e 4. Macroárea ródio-cretense (Gela, Agrigento).

A percepção das linhas de tendência propiciada por estas macroáreas permitiu retomar, com maior profundidade, problemas singulares das apoikias entendidas como as microáreas neste sistema. Esta metodologia, segundo Veronese, permitiu

\footnotetext{
32 È importante registrar que os dados relativos aos 138 locais de culto foram reunidos sem levar em conta a sua relação com uma apoikia. Ibidem, p.538.
} 
em primeira instância, evidenciar as características mais macroscópicas que ligam cidade, santuário e território, e entender dessa forma quais elementos teriam em linha geral condicionado as modalidades de aquisição territorial por parte dos gregos; em um segundo momento por sua vez será possível evidenciar as particularidades que distinguem cada grupo étnico e, no âmbito deste, as colônias individualizadas ${ }^{33}$.

Os resultados do processamento dos dados podem ser visualizados por meio de gráficos e histogramas que indicam, por exemplo, a prevalência da macroárea rodiocretense, formada por Gela e Agrigento, na construçáo de santuários - aproximadamente $45 \%$ do total- sendo que dentre estes, registrase uma grande proporção de santuários localizados na planície agriculturável interiorana, a khóra. Este é um espaço ocupado pelas comunidades locais quando da fundação da apoikia e almejado pelos gregos diante da crescente demanda de terras gerada pelas levas de gregos balcânicos que não cessavam de chegar após o período inicial do estabelecimento.A fundação de Agrigento pelos gelenses, algumas geraçóes depois de estabelecidos na Sicilia, é outro indício do crescimento e prosperidade de Gela muito em decorrência da exploração dos Campi geloi celebrados na antiguidade pela sua fertilidade (VIRGÍlIO, Eneida, III,701).

A plotagem ${ }^{34}$ dos santuários indica como os rios Salso e Dirillo se constituíram nas vias de penetraçáo para o interior.Os dados arqueológicos indicam que a posse da terra na khóra gelense é precedida pela implantação de áreas sagradas e as fontes textuais como Heródoto relatam como, paralelamente, o poder político se fortalece em Gela.A dinastia dos Deinomênidas, família importante e poderosa que dominará o cenário político da Sicília durante décadas inicia sua trajetória com Gélon, tirano que de Gela,

\footnotetext{
${ }^{33}$ Idem.

${ }^{34} \mathrm{Na}$ área total de Gela, Veronese repertoria 28 locais de culto:para cada um apresenta dados completos sobre a localização,contexto geomorfológico e coordenadas geográficas;descrição completa das estruturas subsistentes,materiais e técnicas construtivas;o material votivo encontrado;identificação,quando possível da divindade tutelar;datas de início e término das atividades religiosas;classe de tamanho e bibliografia pertinente. A. T. SMITH. The Political Landscape - Constellations of Authority in Early Complexes Polities. Berkeley and Los Angeles: University of California Press, 2003, pp. 357-433.
} 
onde assume o poder em aprox. 491, torna-se, em 485-4 o governante da próspera Siracusa. ${ }^{35} \mathrm{e}$ deixa em seu lugar, Hiéron, seu irmão (HERÓDOTO, VII, 154-8). É importante lembrar também que à família Deinomênida teria sido concedido, de acordo com Heródoto o privilégio de oficiar os cultos de Deméter e Core, os mais documentados nas áreas de culto gelenses especialmente do interior.

A célebre passagem de Heródoto (VII, 153) a respeito do culto de Deméter-Core em Gela iniciou uma tradição de associação destes cultos com a vida política das apoikias. Conta o historiador:

$\mathrm{O}$ antecessor de Gélon, o que primeiro se estabeleceu em Gela veio da ilha de Telos... Com o decorrer do tempo, seus descendentes tornaram-se sacerdotes das Deusas Ctônias, ofício que mantiveram desde que Telines dele se apoderou. $\mathrm{O}$ modo como Telines conseguiu este ofício é uma estória notável: como resultado de lutas partidárias em Gela, um certo número de homens foi obrigado a deixar a cidade e buscar refúgio em Mactório, nas colinas vizinhas. Estas pessoas foram reintegradas por Telines, não pela força das armas mas simplesmente pela virtude dos objetos sagrados das Deusas Ctônias. Como ou quando ele conseguiu a posse desses objetos não o sei; mas foi nesses objetos e somente neles que Telines se apoiou; e trouxe de volta os exilados com a condição de que seus descendentes conservariam o ofício de sacerdotes...

Desta feita, as fontes documentais sinalizam, neste caso, para uma relação muito próxima entre a posse da terra e o estabelecimento de uma primazia política por parte de uma apoikia. Paralelamente, a instrumentalização de cultos específicos, por governantes fortes como os tiranos, é uma estratégia no sentido da consolidação de seu poder.

A dinâmica entre o político e o religioso também está visível na situação registrada na paisagem sagrada de uma apoikia comparada à paisagem sagrada presente em suas fundaçóes: temos, então, o caso de Agrigento, fundada por Gela, Selinonte, fundada por Mégara Hibléia e Heloro, Casmene, Acrae e Camarina fundadas por Siracusa. Agrigento e Selinonte apresentam

\footnotetext{
${ }^{35}$ As tiranias têm início em Gela entre 505 e 498 e desde o início buscam o domínio não só de terras pertencentes às populaçóes locais como também das outras cidades gregas.
} 
uma grande semelhança na paisagem sagrada se comparadas a Gela e Mégara Hibléia; quantidades e tipos equivalentes de construçóes; Heloro, Casmene, Acrae e Camarina ${ }^{36}$, por outro lado, divergem profundamente de Siracusa, exibindo, ao contrário desta, uma grande escassez de construçóes sagradas. A interpretação estaria na situação de dependência política de Heloro, Casmene, Acrae em relação à Siracusa, que impulsionada pelos projetos expansionistas de seus governantes, funda estes núcleos como postos avançados de defesa do seu território. Afirma-se, assim, uma orientação diferente na infraestruturação dos locais sagrados em apoikias autônomas politicamente como Selinonte e Agrigento em relação às fundaçóes dependentes da polis fundadora, como Heloro, Acrae e Casmene. Veronese sintetiza: “[...] nota-se uma correlação positiva entre a importância política de um centro e a realidade do sagrado" ${ }^{37}$.

Para finalizar a exposição deste estudo de caso, passamos a observar o que ocorre nas áreas vuote, isto é, vazias, desprovidas de áreas sagradas. Em um primeiro caso, trata-se de territórios montanhosos e inóspitos cujo valor estratégico é reduzido e a posse da terra não é o principal objetivo. É o que ocorre, por exemplo, entre Himera e Zancle, na porção setentrional da Sicília onde se localizam os maciços montanhosos Peloritani, Nebrodi e Madonie .Já a faixa interiorana vazia localizada entre Selinonte e Agrigento seria explicada pela diversidade dos interesses econômicos destas apoikias, ou seja, ao padráo de exploração agrícola corresponderia uma paisagem sagrada dinâmica com locais sagrados em atividade, mas nas áreas em que as trocas se constituem na atividade principal, a instituiçáo de uma paisagem sagrada ficaria em segundo plano.

O estudo das paisagens sagradas construídas e reconstruídas continuamente pelas apoikias gregas na Sicilia nos sugere que tal processo obedecia a critérios precisos, objetivos específicos cuja imbricação com a organização política, as formas de poder são nítidas. O estudo de caso que acabamos de apresentar, evidentemente de forma muito sumária, destaca uma

\footnotetext{
${ }^{36} \mathrm{O}$ s dados referentes à paisagem sagrada de Camarina de época arcaica são escassos devido ao pouco trabalho arqueológico desenvolvido na área.

${ }^{37}$ F. ,VERONESE. Lo spazio e la dimenzione del sacro. Santuari Grecia e territorio nella Sicilia arcaica. Padova: Esedra Editrice, 2006, p.627.
} 
dimensão - a religiosa - na constituição de uma paisagem política específica. Se voltarmos às nossas proposiçóes teóricas iniciais e retomarmos as ideias de Smith podemos concluir que, usando as suas palavras,

as paisagens são produzidas em muitas esferas diferentes de autoridade (por exemplo, famílias constroem casas, grupos corporativos constroem assentamentos, governantes estabelecem cidades). Como resultado, uma paisagem emerge como um palimpsesto de relaçóes de autoridade. Esta pluralidade na produção [da paisagem] cria potencial para uma significante 